\title{
Article \\ Comparative Investigation on Corrosion Resistance of Stainless Steels Coated with Titanium Nitride, Nitrogen Titanium Carbide and Titanium-Diamond-like Carbon Films
}

\author{
Jia Lou ${ }^{1}$, Zonglong Gao ${ }^{1}$, Jie Zhang ${ }^{2,3, *}$, Hao He ${ }^{4, *}$ and Xinming Wang ${ }^{1}$ \\ 1 School of Materials Science and Engineering, Xiangtan University, Xiangtan 411105, China; \\ lou3166@xtu.edu.cn (J.L.); gaozonglong1996@163.com (Z.G.); wangxm@xtu.edu.cn (X.W.) \\ 2 School of Stomatology, Hunan University of Chinese Medicine, Changsha 410036, China \\ 3 Changsha Stomatological Hospital, Changsha 410000, China \\ 4 School of Microelectronics and Materials Engineering Research Centre for Materials Science and Engineering, \\ Guangxi University of Science and Technology, Liuzhou 545006, China \\ * Correspondence: kqzj@hnucm.edu.cn (J.Z.); 100001865@gxust.edu.cn (H.H.)
}

check for updates

Citation: Lou, J.; Gao, Z.; Zhang, J.; He, H.; Wang, X. Comparative Investigation on Corrosion Resistance of Stainless Steels Coated with Titanium Nitride, Nitrogen Titanium Carbide and Titanium-Diamond-like Carbon Films. Coatings 2021, 11, 1543. https://doi.org/10.3390/ coatings11121543

Academic Editor: Alina Vladescu

Received: 19 November 2021 Accepted: 13 December 2021 Published: 15 December 2021

Publisher's Note: MDPI stays neutral with regard to jurisdictional claims in published maps and institutional affiliations.

Copyright: (c) 2021 by the authors. Licensee MDPI, Basel, Switzerland. This article is an open access article distributed under the terms and conditions of the Creative Commons Attribution (CC BY) license (https:/ / creativecommons.org/licenses/by/ $4.0 /)$.

\begin{abstract}
In this study, the corrosion resistance of titanium nitride (TiN), nitrogen titanium carbide (TiCN) and titanium-diamond-like carbon (Ti-DLC) films deposited on 316L stainless steel (SS) were compared via differences in the surface and section-cross morphologies, open circuit potential tests, electrochemical impedance spectroscopy and potentiometric tests. The corrosion resistance of the TiCN and Ti-DLC films significantly improved because of the titanium carbide (TiC) crystals that obstruct the corrosive species penetrating the as-deposited film in the electrolyte atmosphere. TiN exhibited the lowest corrosion resistance because of its low thickness and high volume of defects. The Ti-DLC film showed the lowest corrosion current density (approximately $4.577 \mu \mathrm{A} / \mathrm{cm}^{2}$ ) and thickness reduction (approximately $0.12 \mu \mathrm{m}$ ) in different electrolytes, particularly those with high $\mathrm{Cl}^{-}$and $\mathrm{H}^{+}$concentrations, proving to be the most suitable corrosion protection material for $316 \mathrm{~L}$ SS substrates.
\end{abstract}

Keywords: dental brace; anticorrosive coating; electrochemical test; titanium-diamond-like carbon film; titanium carbide cluster

\section{Introduction}

Dental braces are frequently used in the field of orthodontics because they arrange misplaced teeth in their normal positions, leading to improved oral health [1-3]. Conventionally used orthodontic appliances are mainly made of stainless steel (SS), which has a favorable combination of mechanical properties, corrosion resistance and cost effectiveness [4]. However, stainless steel is susceptible to wear and corrosion in an oral environment with changing $\mathrm{pH}$ values, high concentration of $\mathrm{Cl}^{-}$and other ions, such as $\mathrm{Na}^{+}, \mathrm{K}^{+}$and $\mathrm{F}^{-}$[5-8]. Friction or collision causes stress corrosion, which accelerates brace failure and leads to the release of harmful nickel ions [9-11].

Anticorrosive coatings are often used to improve the corrosion resistance and wear resistance of dental materials to resolve these issues. TiN coatings demonstrate a high hardness, low coefficient of friction (COF), and high biocompatibility [12,13]. Liu et al. found that the corrosion current densities of TiN-coated specimens were approximately three orders of magnitude lower than those of uncoated specimens, indicating that TiN could protect substrates [14]. In contrast, Kao et al. revealed that TiN did not increase the anticorrosion ability of standard dental bracket because TiN-plated and non-TiN-plated brackets released detectable ions into the test solution. These included $\mathrm{Ni}^{2+}, \mathrm{Cr}^{3+}$ and $\mathrm{Fe}^{3+}$, suggesting differences in the porosity of the coatings [15]. TiCN coatings have attracted attention due to low internal stress, excellent tribological properties and nontoxicity [16-18]. Numerous studies have shown that doping C in TiN has a double-sided 
effect [19-21]. Wang et al. reported that when the $\mathrm{C}$ content of $\mathrm{TiCN}$ is $2.05 \%$, the charge transfer resistance $\left(R_{\mathrm{ct}}\right)$ increases from $8.8 \times 10^{5} \Omega \cdot \mathrm{cm}^{2}$ in TiN to $6.49 \times 10^{6} \Omega \cdot \mathrm{cm}^{2}$ due to formation of $\alpha-\mathrm{CN}_{\mathrm{x}}$, leading to a more stable electrochemical performance. When the $\mathrm{C}$ content increases to $2.46 \%, \alpha-\mathrm{C}$ is formed, deteriorating the corrosion resistance of TiCN in simulated body fluids [22]. With the increasing demand for comfortable and durable dental braces, diamond-like carbon (DLC) films are extensively being used in protective coatings for orthodontic materials. Ti-DLC films are formed through the co-deposition of DLC and biocompatible Ti. This process not only enhances the mechanical properties of the surface, such as hardness, toughness and tribological performance, but also improves its corrosion resistance, particularly stress corrosion resistance [23-26].

The tribological performances of 316L SS substrates coated with TiN, TiCN, and TiDLC films were compared in our previous studies. The Ti-DLC film showed the lowest COF because the surface contains $\mathrm{sp}^{2-}$ carbon (graphite-like carbon) that has a self-lubricating effect [27]. In addition, the Ti-DLC coatings demonstrated excellent corrosion resistance and electrochemical stability. Zhang et al. reported that Ti-DLC has a higher corrosion potential and lower corrosion current than those of the SS substrate, indicating its superior ability to protect the substrate [28]. Konkhunthot et al. also reported that the corrosion current was reduced by two orders of magnitude owing to formation of a Ti-DLC film on 304 SS [29]. More recently, Wongpanya et al. incorporated and interlayered Ti into Ti-DLC film, finding that the double-interlayer enhanced pitting corrosion resistance of the film [30]. Zhou et al. reported that excessive TiC acted as defect points in DLC films and weakened the corrosion resistances of the film. They observed a higher corrosion current density and a lower corrosion potential in Ti-DLC films with Ti contents of 5.31 at.\% compared with 0.46 at.\% [31].

The Ti-DLC film in our previous work had a modest hardness, the lowest roughness and COF; however, electrochemical corrosion tests were not performed. Studies comparing the corrosion mechanism of TiN, TiCN and Ti-DLC coatings under artificial saliva condition are rare, particularly with fluctuating $\mathrm{pH}$ value and $\mathrm{Cl}^{-}$concentrations. In this study, 316L SS substrates coated with TiN, TiCN and Ti-DLC were prepared by multi-arc ion plating. Open circuit potential (OCP) tests, electrochemical impedance spectroscopy (EIS) observations, potentiometric polarization measurements, and corrosion morphology tests were conducted in artificial saliva and electrolyte with different $\mathrm{pH}$ and $\mathrm{Cl}^{-}$concentrations, and the film showing the best anticorrosion performance was identified. This study provides an experimental and theoretical basis for the production, application and improvement of orthodontic braces in future.

\section{Experiment}

The 316L stainless steel plates (approximate size of $15 \times 15 \times 2 \mathrm{~mm}^{3}$ ) were sanded and polished using sandpaper (\#200-\#2000) prior to deposition. These polished surfaces were ultrasonically cleaned in ethanol for $10 \mathrm{~min}$ and deionized water for $5 \mathrm{~min}$, to remove residual liquid. TiN, TiCN and Ti-DLC films were deposited on the surface of these plates via multi-arc ion plating. The details of the materials and parameters of coating processes are obtained from our previous studies [27].

The surface morphologies and thickness of the films after the electrochemical tests were observed using field-emission scanning electron microscopy (FEI Nova NanoSEM230, Chicago, IL, USA).

The electrochemical properties of the samples were characterized using $\mathrm{CH}$ 660 e electrochemical workstation (ChenHua, Shanghai, China). The traditional three-electrode cell system was used to examine the electrochemical behavior of the samples; a $2.25 \mathrm{~cm}^{2}$ area of the sample was exposed as the working electrode; an $\mathrm{Ag} / \mathrm{AgCl}$ electrode acted as the reference electrode, and a titanium slice was used as the counter electrode. The samples were immersed in an artificial saliva solution for $4000 \mathrm{~s}$ to evaluate the OCP at $37^{\circ} \mathrm{C}$. During EIS, the measurement frequency was swept from $10^{-2}$ to $10^{5} \mathrm{~Hz}$, and a sinusoidal disturbance voltage of $10 \mathrm{mV}$ was applied. The EIS data were imported into 
ZSimpWin software for further fitting and analysis of the corresponding equivalent circuit (EC). The scanning potential ranged from $-1.5 \mathrm{~V}$ vs. $\mathrm{Ag} / \mathrm{AgCl}$ to $1.5 \mathrm{~V}$ vs. $\mathrm{Ag} / \mathrm{AgCl}$ at a scanning rate of $2 \mathrm{mV} / \mathrm{s}$ was used for obtaining the potentiometric polarization curves. The corrosion current density of the samples was estimated from the polarization curves using the Tafel extrapolation fitting method. Inhibition efficiencies (IE, $\eta$ ) were calculated by fitted corrosion current densities $\left(\mathrm{I}_{\mathrm{corr}}\right)$ based on the following equation:

$$
\eta(\%)=\left(1-\frac{I_{\text {corr }}}{I_{\text {corr }}^{0}}\right) \times 100 \%
$$

where $\mathrm{I}_{\text {corr }}$ and $\mathrm{I}_{\text {corr }}^{0}$ are current densities of treated and naked steel, respectively.

The EIS and potentiometric polarization measurements were performed in the artificial saliva solution, those contents were determined according to the standard of the corrosion resistance examination of SS and NiTi orthodontic wires [32], as illustrated in Table 1. The $\mathrm{pH}$ of the artificial saliva solution was approximately 6.8 .

Table 1. Ingredients of the artificial saliva solution.

\begin{tabular}{ccccccc}
\hline Ingredient & $\mathbf{N a C l}$ & $\mathbf{K C l}$ & $\mathbf{C a C l}_{\mathbf{2}}$ & $\mathbf{K}_{\mathbf{2}} \mathbf{P O}_{\mathbf{4}}$ & $\mathbf{K S C N}$ & $\mathbf{C H}_{\mathbf{4}} \mathbf{N}_{\mathbf{2}} \mathbf{O}$ \\
\hline Content $(\mathrm{mg} / \mathrm{L})$ & 400 & 400 & 795 & 690 & 300 & 1000 \\
\hline
\end{tabular}

To evaluate the effects of $\mathrm{pH}$ values and $\mathrm{Cl}^{-}$concentrations on the corrosion resistance, potentiometric polarization curve tests were performed in solutions with different $\mathrm{NaCl}$, citric acid $\left(\mathrm{H}_{3} \mathrm{Cit}\right)$ and potassium citrate $\left(\mathrm{K}_{3} \mathrm{Cit}\right)$ concentrations, as given in Table 2 . The method of operation is already described.

Table 2. Electrolyte concentrations in 1 L electrolyte solutions used for electrochemical measurements.

\begin{tabular}{ccccc}
\hline Concentration $(\mathrm{g} / \mathrm{L})$ & $\mathbf{( 0 . 9 \% , 6 . 6 )}$ & $\mathbf{( 0 . 9 \% , 3 )}$ & $\mathbf{( 3 \% , 6 . 6 )}$ & $\mathbf{( 3 \% , 3 )}$ \\
\hline $\mathrm{NaCl}(\mathrm{mL})$ & 9 & 9 & 30 & 30 \\
$0.1 \mathrm{M} \mathrm{H}_{3} \mathrm{Cit}(\mathrm{mL})$ & 5.6 & 74.4 & 5.6 & 74.4 \\
$0.1 \mathrm{M} \mathrm{K}_{3} \mathrm{Cit}(\mathrm{mL})$ & 74.4 & 5.6 & 74.4 & 5.6 \\
\hline
\end{tabular}

For easy understanding, the notation $(\mathrm{X} \%, \mathrm{Y})$ is used to represent the electrolyte solution with an $\mathrm{NaCl}$ concentration of $\mathrm{X} \%$ and a $\mathrm{pH}$ value of $\mathrm{Y}$.

Before conducting the electrochemical tests, the samples were immersed in artificial saliva for $24 \mathrm{~h}$, to ensure that their surfaces were completely passivated. All the electrochemical tests were repeated at least thrice, and showed roughly the same values and trends.

\section{Results and Discussion}

\subsection{Surface Morphologies and Composition Analysis}

Our previous study [27] showed the as-prepared surfaces of 316L SS substrate was smooth, and the surface of TiN had some particles and pinholes. Moreover, TiCN and Ti-DLC had many nanocrystal clusters after physical vapor deposition (PVD). According to the XRD data, these clusters were the $\mathrm{TiC}$ which was generated by the reaction of $\mathrm{Ti}$ and $\mathrm{C}$ during deposition. Additionally, the thicknesses of the TiN, TiCN, and Ti-DLC films were $2.05,4.10$ and $4.48 \mu \mathrm{m}$, respectively. The Ti-DLC was found to exhibit the best adhesion and anti-wear properties.

Figure 1 demonstrates the surface morphologies of the 316L SS substrate and three films after the electrochemical tests in artificial saliva. The substrate surface is generally smooth, and only the diameter of the holes has increased, owing to the low-degree erosion of SS in a relatively mild saliva environment. Furthermore, the surfaces of all three films have nanocrystal clusters and pinholes. This because the TiC particles exist in the TiCN and Ti-DLC films, functioning as seeds and gradually growing into cluster defects during 
deposition. In TiN samples, particles and pinholes are common growth defects resulting from deposition, which are always generated in the bulges and cavities on the substrate [33]. However, the number of particles of the TiN surface are far more than those of $\mathrm{TiCN}$ and Ti-DLC films after polarization tests in artificial saliva. This phenomenon is mainly because of the superior electrochemical stability of TiN clusters compared with those of $\mathrm{TiC}$ on Ti-DLC films; thus, TiC preferably dissolves in artificial saliva [34].
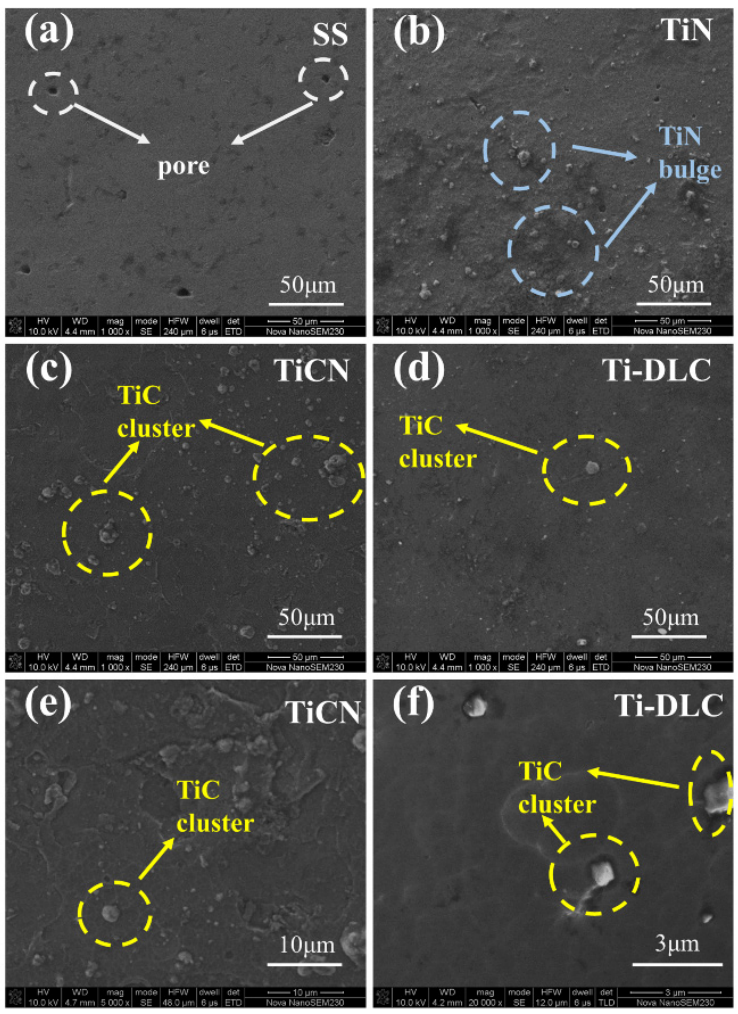

Figure 1. Surface morphologies of four samples after polarization tests in artificial saliva. (a) 316L SS, $1000 \times$; (b) TiN, 1000×; (c) TiCN, 1000×; (d) Ti-DLC, 1000×; (e) TiCN, 5000×; (f) Ti-DLC, 20,000×.

\subsection{OCP Test}

Figure 2 displays the $\mathrm{OCP}$ variation curves of the four samples in artificial saliva at $37^{\circ} \mathrm{C}$ within $4000 \mathrm{~s}$. According to the standard test method for measuring potentiodynamic polarization resistance, the basic stabilization value of OCP can be used as valid data after $55 \mathrm{~min}$. The 316L SS substrate shows the most negative OCP $(-0.156 \mathrm{~V})$. In contrast, the three films have higher potentials, indicating that all the films can significantly enhance the corrosion resistance stability of 316L SS substrate. Among them, TiCN possess the most positive electrode potential $(0.092 \mathrm{~V})$ and highest stability. Moreover, the Ti-DLC film shows a slight negative deviation in the OCP value, indicating the inferior chemical stability of the coating. This phenomenon results in a dense surface structure and relatively high thickness of the TiCN film, yielding excellent electrochemical stability. Although Ti-DLC has the highest thickness, it contains many clusters that could have dissolved in the artificial saliva, leading to a negative deviation in the OCP value. The TiN film has a lower potential and larger fluctuation than other films. Its inferior chemical stability is because of its low thickness and several defects. 


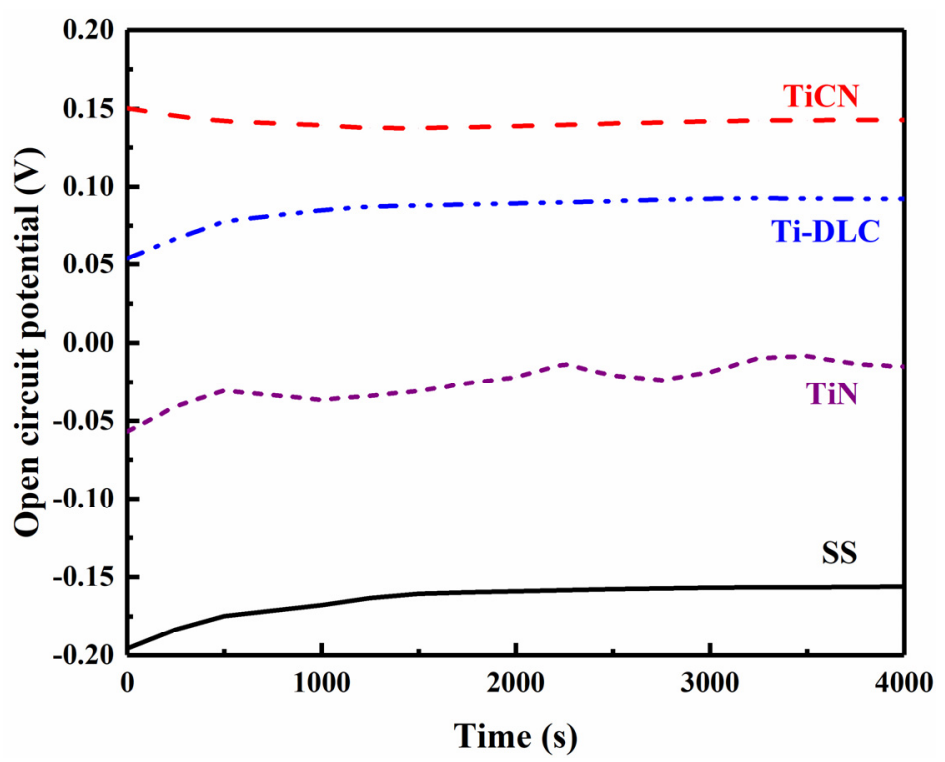

Figure 2. OCP of four samples in artificial saliva at $37^{\circ} \mathrm{C}$.

\subsection{EIS Results}

To evaluate the corrosion protection properties of the films, EIS measurements were carried out in artificial saliva at $37^{\circ} \mathrm{C}$. The Nyquist (including the locally amplified inner graphic) and Bode plots of the samples are shown in Figure 3a,b, respectively. The diameter of the capacitive loop in the Nyquist plots corresponds to the corrosion resistance. Figure $3 a$ demonstrates that the corrosion resistances of the SS substrate, TiCN, Ti-DLC and TiN film decrease successively. The same order is found for the "log Z" values in Figure 3b. According to Zhang's research, the impedance modulus at the lowest frequency $\left(Z_{\mathrm{f}}=0.01 \mathrm{~Hz}\right)$ is another parameter in the Bode plot for evaluating the corrosion protection capability of the films; a greater impedance suggests a better corrosion resistance [35].

In addition, the "phase angle" of the Bode plot and the locally amplified graphic of $10-10 \mathrm{k} \mathrm{Hz}$ are illustrated in Figure 3c,d. As shown in Figure 3c, the order of the sample corrosion resistance (Figure $3 c$ ) was consistent with the Nyquist plots, owing to the improvement of the passive film, that increased the phase angle [36]. Figure $3 \mathrm{c}$ and $\mathrm{d}$ show the 316L SS has only one plateau region and all the films have two; this indicates that the EC of the 316L SS has one time constant, but the three films have two.

Considering a passive film formed on the 316L SS surface and electrochemical reactions took place at the metal/film interface, the best fitting EC simulated from the EIS results using the ZSimpWin software, is illustrated in Figure 4. Additionally, the parameters are listed in Table 3; the chi-squared $\left(X^{2}\right)$ value in the order of $10^{-3}$ to $10^{-4}$ indicating the good fit has been obtained with the suggested EC models [37]. This method has been used to fit titanium alloys and metal-DLC films in many studies [22,38,39]. In the circuits (a), the $R_{s}, R_{1}$ and $R_{2}$ represented the solution resistance, porous layer resistance, and the dense layer resistance, respectively. In the circuits $(b)$, the $R_{S}, R_{f}$ and $R_{c t}$ represented the solution resistance, film resistance and the charge transfer resistance, respectively. The $C_{1}$ and $C_{2}$ were the surface layer capacitance and inner layer capacitance; additionally, $C_{d l}$ represented the double-layer capacitance. In Figure $4 a, R_{2}$ is $25,320 \Omega \cdot \mathrm{cm}^{2}$ indicates that the oxide layer produced via the self-passivation of the SS substrate can effectively improve its corrosion resistance. In Figure $4 b$, the maximum $R_{f}\left(637.8 \Omega \cdot \mathrm{cm}^{2}\right)$ was observed in TiCN, indicating its excellent corrosion resistance. $R_{f}$ of Ti-DLC and TiN are $329.1 \Omega \cdot \mathrm{cm}^{2}$ and $154.9 \Omega \cdot \mathrm{cm}^{2}$, respectively. It worth noting that $\mathrm{R}_{\mathrm{ct}}$ of $\mathrm{TiCN}$ is similar to that of Ti-DLC, implying that the charge transfer at both these substrate interfaces is effectively prevented, thus contributing to their high corrosion resistance. This enhancement in corrosion resistance may be related to the dense surface structure and relatively high thickness of TiCN. Furthermore, Ti-DLC has the highest thickness, but contains many clusters that dissolved into the artificial saliva; 
thus, its $\mathrm{R}_{\mathrm{f}}$ value is smaller than TiCN. Moreover, the main reason for the poor corrosion resistance of the TiN film is its low thickness and high volume of defects.
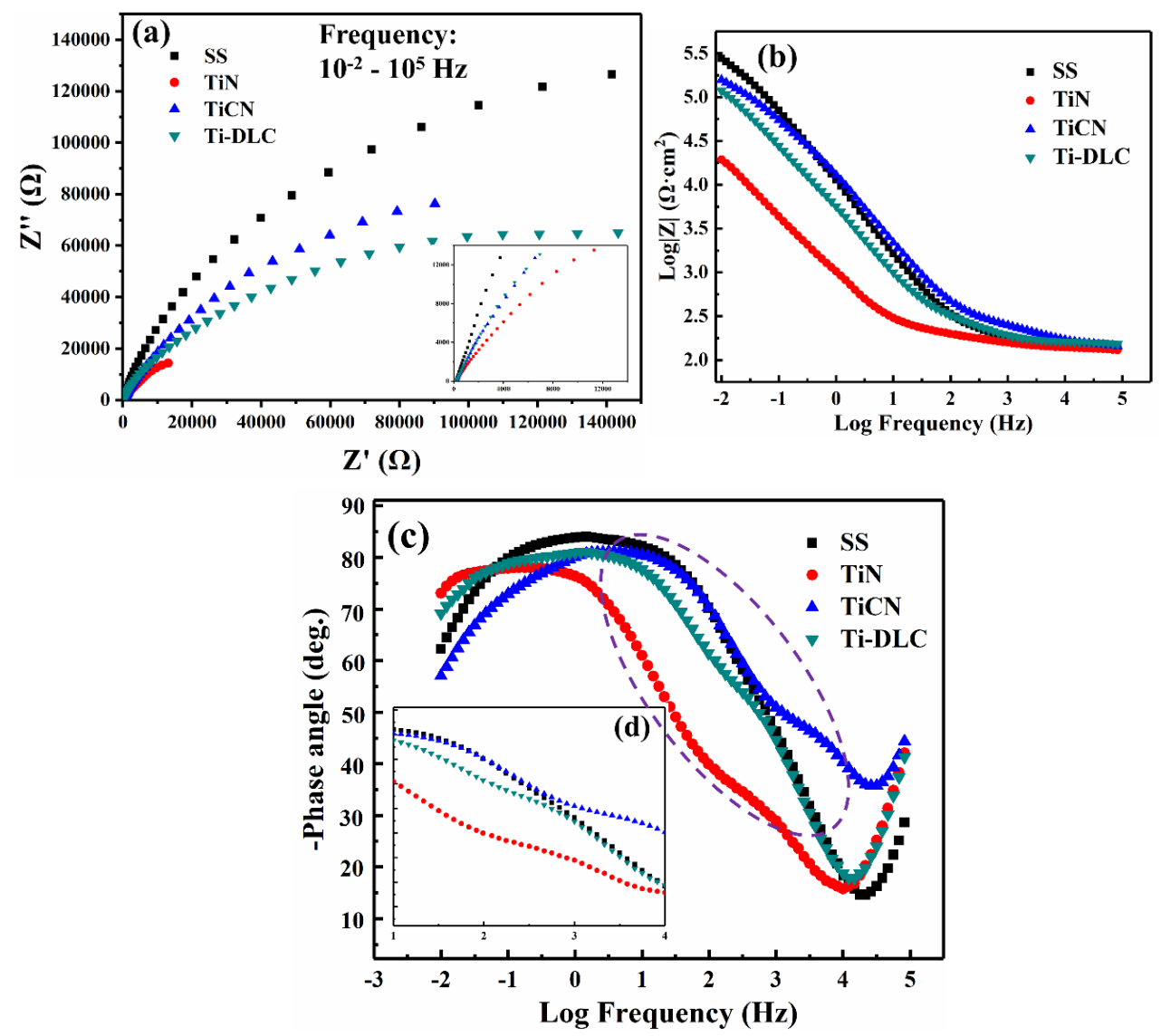

Figure 3. Nyquist and Bode plots of the four samples in artificial saliva. (a) Nyquist plots of the four samples; (b) Bode plots of the four samples; (c) Phase angle of bode plots; insertion (d) locally amplified graphic of phase angle.
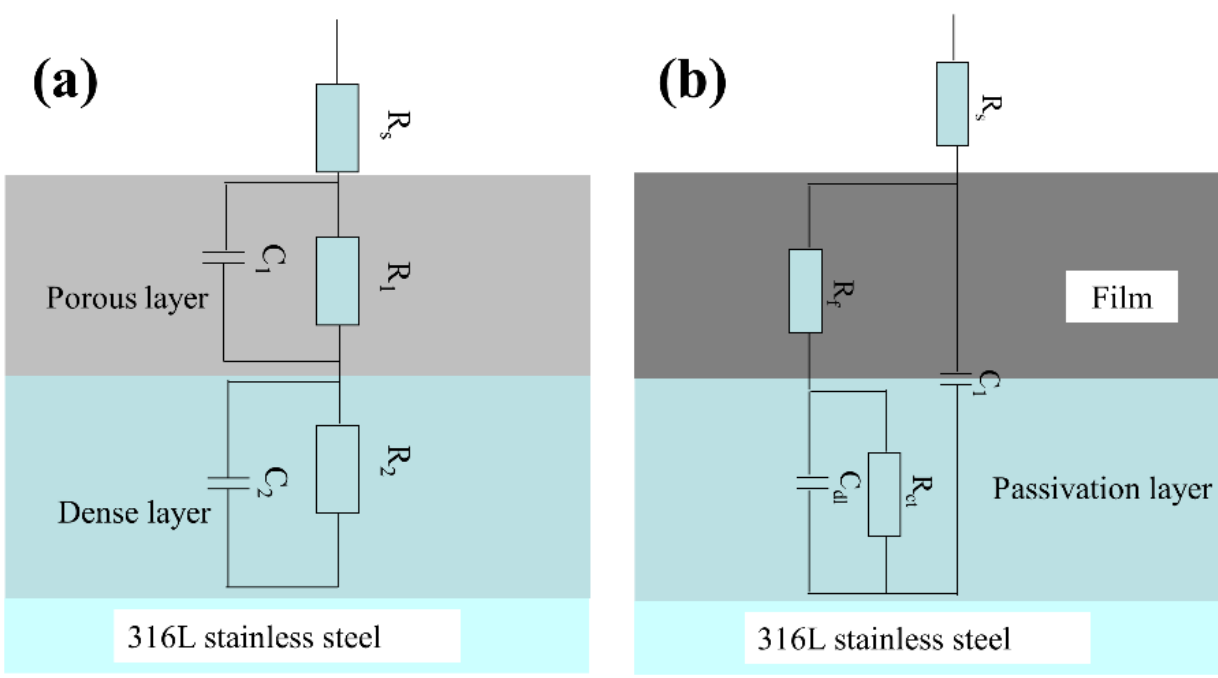

Figure 4. ECs of bare SS (a) and film-coated SS (b) used for fitting the impedance data. 
Table 3. Thicknesses and EC results of 316L SS substrate, TiN, TiCN and, Ti-DLC films.

\begin{tabular}{|c|c|c|c|c|c|c|}
\hline Sample & $\begin{array}{c}R_{\mathrm{s}} \\
\left(\Omega \cdot \mathrm{cm}^{2}\right)\end{array}$ & $\begin{array}{c}R_{1} / R_{f} \\
\left(\Omega \cdot \mathrm{cm}^{2}\right)\end{array}$ & $\begin{array}{c}R_{2} / R_{c t} \\
\left(\Omega \cdot \mathrm{cm}^{2}\right)\end{array}$ & $\begin{array}{c}\mathrm{C}_{1} \\
\left(\mathrm{~F} / \mathrm{cm}^{2}\right)\end{array}$ & $\begin{array}{l}\mathrm{C}_{2} / \mathrm{C}_{\mathrm{dl}} \\
\left(\mathrm{F} / \mathrm{cm}^{2}\right)\end{array}$ & $\begin{array}{c}\text { Chi-Squared } \\
\left(X^{2}\right)\end{array}$ \\
\hline SS & 17.85 & 218.3 & 25,320 & $1.297 \times 10^{-4}$ & $1.775 \times 10^{-4}$ & $2.3 \times 10^{-3}$ \\
\hline $\mathrm{TiN}$ & 17.82 & 154.9 & 2230 & $9.884 \times 10^{-4}$ & $3.251 \times 10^{-3}$ & $7.2 \times 10^{-4}$ \\
\hline $\mathrm{TiCN}$ & 21.16 & 637.8 & 11,760 & $1.404 \times 10^{-4}$ & $3.959 \times 10^{-4}$ & $4.5 \times 10^{-3}$ \\
\hline Ti-DLC & 20.22 & 329.1 & 10,250 & $1.574 \times 10^{-4}$ & $3.240 \times 10^{-4}$ & $5.3 \times 10^{-4}$ \\
\hline
\end{tabular}

\subsection{Potentiometric Test}

The Tafel polarization curves of the four samples immersed in artificial saliva are demonstrated in Figure 5a. A pronounced anodic peak emerged within the potential range from 0.592 to $0.618 \mathrm{~V}$ vs. $\mathrm{Ag} / \mathrm{AgCl}$ and 0.185 to $0.223 \mathrm{~V}$ vs. $\mathrm{Ag} / \mathrm{AgCl}$, for $316 \mathrm{LSS}$ and TiN, respectively. The anodic peak was attributed to the film erosion in artificial saliva because the corrosive mediums can penetrate defects and microcracks of the film [40]. For Ti-DLC, it possessed a smooth anodic curve and a negative passive region, suggesting the less corrosion [26]. Normally, a low corrosion current density $\left(\mathrm{I}_{\text {corr }}\right)$ implies high corrosionprotection performance distinctly [37]. The $\mathrm{I}_{\text {corr }}$ was calculated using Tafel extrapolation and is summarized in Figure $5 \mathrm{~b}$. The Ti-DLC film possesses the lowest $\mathrm{I}_{\text {corr }}$ in artificial saliva, indicating the best corrosion resistance. This result is consistent with the polarization curve in Figure 5a. Its $\mathrm{I}_{\text {corr }}$ is considerably lower than that of the TiCN film, due to its ultrahigh thickness and that its surface clusters have already dissolved already. Wang et al. also reported an increase in electrochemical stability after the surface clusters dissolved [22]. They found that the TiCN coating with many clusters on the surface showed poor stability during the EIS test. With the dissolution of its surface clusters, a smoother surface was formed, leading to better corrosion resistance in subsequent potentiometric tests. The $\mathrm{I}_{\text {corr }}$ of Ti-DLC is higher than other similar DLC coatings, which may be due to the larger surface roughness $(10.4 \mathrm{~nm}$ ) than the others (approximately $4.2 \mathrm{~nm}$ ) in this study. Other studies have shown large surface roughness weakens the corrosion resistance [28,31]. In addition to film thickness and roughness, the corrosion resistance may be affected by the degree of crystallization and grain size. These parameters can be controlled by the substrate temperature, deposition speed, external electric field, gas flow rate, and pressure. This could be the focus of a future study. The polarization curve for TiN shows a passive region in a narrower potential range and the highest $\mathrm{I}_{\text {corr }}$, demonstrating the formation of an inferior stable passive layer compared with those of the other films.
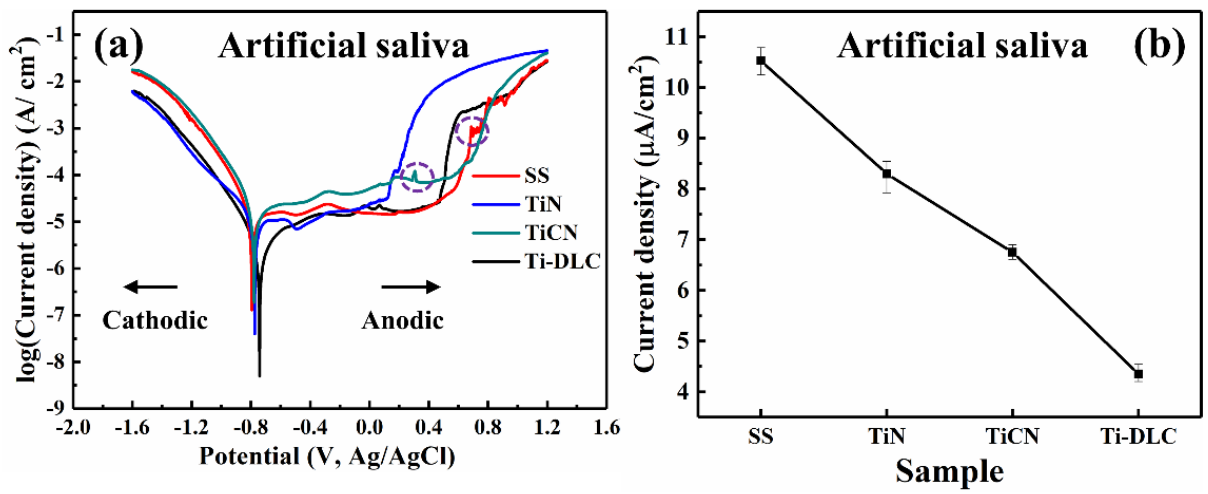

Figure 5. Polarization plots and corrosion current densities of the four samples in artificial saliva. (a) Polarization plots of the four samples; (b) corrosion current densities of the four samples.

The electrochemical behaviors of the samples in different electrolyte systems were analyzed to evaluate the effects of the oral microenvironment on corrosion resistance, and the data are presented in Figure 6. The performance of 316L SS is different from that discussed in Section 3.3. The polarization curves of the 316L SS shift toward a more 
positive region with increases in the $\mathrm{Cl}^{-}$or $\mathrm{H}^{+}$concentrations. In addition, its $\mathrm{I}_{\text {corr }}$ increased significantly, suggesting that the corrosion resistance of 316L SS was significantly affected by the changes in the electrolyte systems. This is because 316L SS contains corrosionresistant elements, namely $\mathrm{Cr}$ and $\mathrm{Ni}$, capable of forming a dense oxide film on the surface of the material [41]; thus, the best corrosion resistance was obtained from the EIS results. However, at high concentrations of $\mathrm{Cl}^{-}$, the $\mathrm{Cl}^{-}$were preferentially adsorbed onto 316 LS surface because of their affinity to metals. The locally adsorbed $\mathrm{Cl}^{-}$ions led to enhanced dissolution of the passive layer at these sites, thinning of the passive layer and eventually active dissolution. Further, the chemical activity of the $\mathrm{H}^{+}$cations significantly accelerated this process [42]. Figure 5 e shows, the TiN films are insensitive to changes in $\mathrm{pH}$. However, as the concentration of $\mathrm{Cl}^{-}$increased from $0.9 \%$ to $3 \%$, $\mathrm{I}_{\text {corr }}$ increased from 10.588 to $37.51 \mu \mathrm{A} / \mathrm{cm}^{2}$. According to Liu, during the dissolution of TiN, the $\mathrm{H}^{+}$ions are neutralized by the $\mathrm{N}$ ions released from the TiN, transforming into $\mathrm{NH}_{4}{ }^{+}$[43]. However, in a $\mathrm{Cl}^{-}$-rich atmosphere, the TiN could not prevent $\mathrm{Cl}^{-}$from penetrating the film completely because of its low thickness and imperfections. Once the corrosive ions penetrate the coating through these small channels, a galvanic effect is formed at the interface between the coating and substrate, which accelerates the corrosion rate because of the difference in composition. Thus, $\mathrm{I}_{\text {corr }}$ of TiN is considerably higher than that of the 316L SS substrate in the $(3 \%, 3)$ electrolyte [44]. The protection mechanism of the TiN film is illustrated in Figure 7a.

The TiCN and Ti-DLC films exhibited excellent electrochemical stability in different electrolytes. The main reason for this phenomenon is that the $\mathrm{TiC}$ crystals can obstruct the path of the corrosive species penetrating the as-deposited film. The corrosive medium hardly contacted the 316L SS substrate. Hence, the corrosion resistance of the bracket is improved $[44,45]$. However, note that $\mathrm{I}_{\text {corr }}$ of $\mathrm{TiCN}$ in the $(3 \%, 6.6)$ electrolyte is significantly higher than that in other concentrations. A possible reason is that the thickness of the TiCN film is lower than that of the Ti-DLC film; This means several $\mathrm{Cl}^{-}$and $\mathrm{H}^{+}$can easily penetrate the film/sublayer interface to react with the substrate. For Ti-DLC, the corrosion current increases slightly at concentrations of high $\mathrm{Cl}^{-}$and $\mathrm{H}^{+}$ions, owing to its ultrahigh thickness and self-passivation effect on the electrolyte. Further corrosion can be prevented, thereby protecting the 316L SS substrate. The corrosion-resistant mechanism of the Ti-DLC film is shown in Figure $7 \mathrm{~b}$. All parameters of the four samples calculated using Tafel extrapolation are summarized in Table 4.

Table 4. All parameters of four sample calculated using Tafel extrapolation.

\begin{tabular}{|c|c|c|c|c|c|c|}
\hline Electrolyte & Sample & $E_{\text {corr }}(V)$ & $I_{\text {corr }}(A)$ & $\beta a(d e c)$ & $\beta a(\mathrm{dec})$ & $\eta(\%)$ \\
\hline \multirow{4}{*}{ artificial } & SS & -0.7936 & $1.05 \times 10^{-5}$ & 690 & -134 & - \\
\hline & $\mathrm{TiN}$ & -0.7508 & $0.83 \times 10^{-5}$ & 106 & -167 & 20.95 \\
\hline & $\mathrm{TiCN}$ & -0.7342 & $0.68 \times 10^{-5}$ & 225 & -108 & 35.24 \\
\hline & Ti-DLC & -0.7292 & $0.44 \times 10^{-5}$ & 750 & -225 & 58.09 \\
\hline \multirow{4}{*}{$0.9 \%, 6.6$} & SS & -0.7806 & $0.91 \times 10^{-5}$ & 125 & -171 & - \\
\hline & $\mathrm{TiN}$ & -0.643 & $0.71 \times 10^{-5}$ & 225 & 667 & 21.98 \\
\hline & $\mathrm{TiCN}$ & -0.8038 & $0.55 \times 10^{-5}$ & 208 & -113 & 39.56 \\
\hline & Ti-DLC & -0.425 & $0.28 \times 10^{-5}$ & 667 & -417 & 69.23 \\
\hline \multirow{4}{*}{$0.9 \%, 3$} & SS & -0.6544 & $2.61 \times 10^{-5}$ & 125 & -225 & - \\
\hline & $\mathrm{TiN}$ & -0.4787 & $1.06 \times 10^{-5}$ & 75 & -105 & 59.39 \\
\hline & $\mathrm{TiCN}$ & -0.4528 & $0.98 \times 10^{-5}$ & 334 & -149 & 62.45 \\
\hline & Ti-DLC & -0.4088 & $0.46 \times 10^{-5}$ & 183 & -417 & 82.24 \\
\hline \multirow{4}{*}{$3 \%, 3$} & SS & -0.7711 & $2.92 \times 10^{-5}$ & 746 & 291 & - \\
\hline & $\mathrm{TiN}$ & -0.727 & $3.41 \times 10^{-5}$ & 91 & -646 & - \\
\hline & $\mathrm{TiCN}$ & -0.5396 & $2.06 \times 10^{-5}$ & 159 & -158 & 29.45 \\
\hline & Ti-DLC & -0.4571 & $0.61 \times 10^{-5}$ & 747 & -118 & 79.11 \\
\hline \multirow{4}{*}{$3 \%, 6.6$} & SS & -0.86 & $1.96 \times 10^{-5}$ & 167 & -91 & - \\
\hline & $\mathrm{TiN}$ & -0.8815 & $3.76 \times 10^{-5}$ & 375 & 201 & - \\
\hline & $\mathrm{TiCN}$ & -0.5373 & $1.54 \times 10^{-5}$ & 146 & -267 & 21.43 \\
\hline & Ti-DLC & -0.4118 & $0.46 \times 10^{-5}$ & 167 & -133 & 76.53 \\
\hline
\end{tabular}



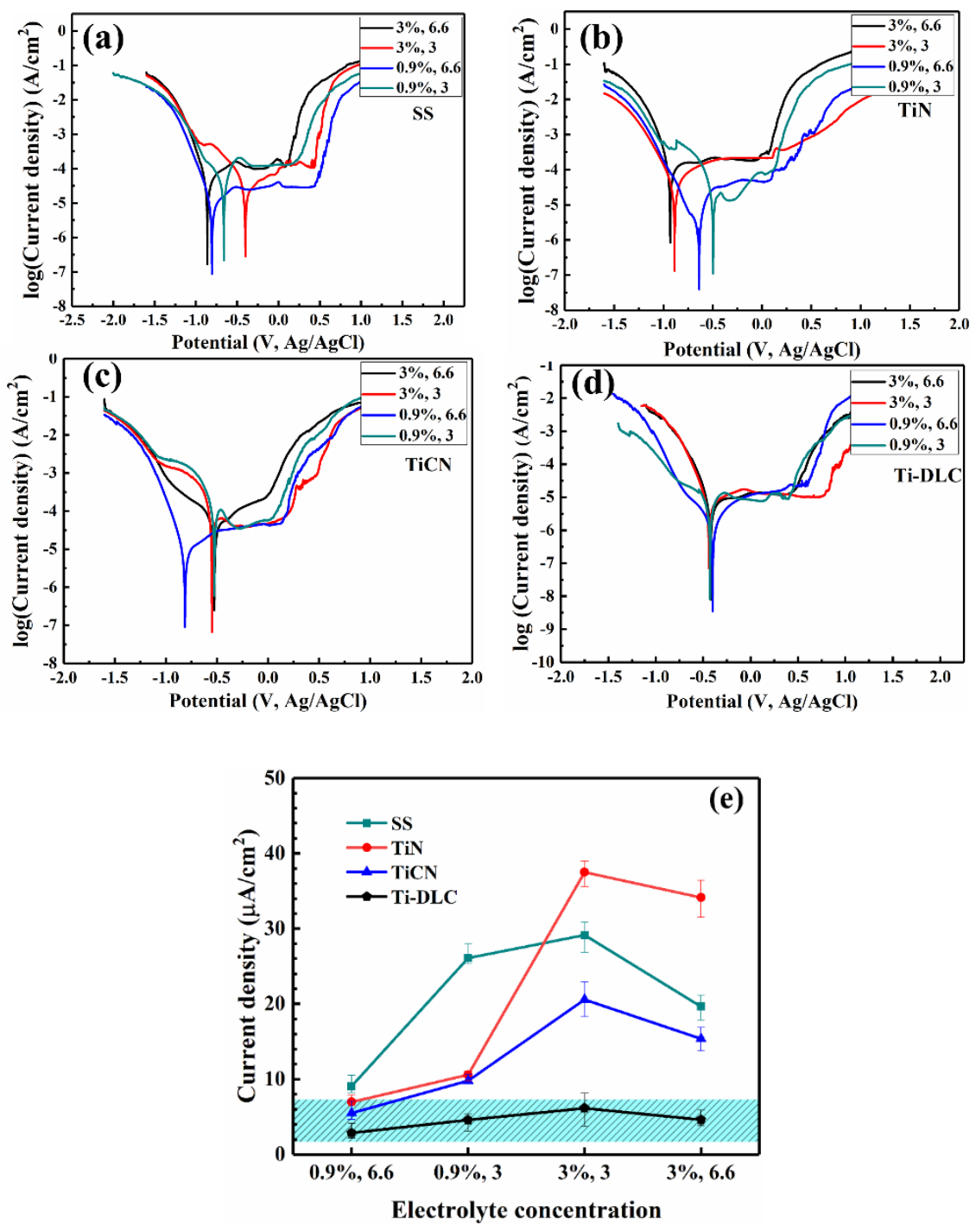

Figure 6. Polarization plots and corrosion current densities of the four samples in different electrolytes. (a) Polarization plots of SS; (b) Polarization plots of TiN; (c) Polarization plots of TiCN; (d) Polarization plots of Ti-DLC; (e) corrosion current densities of the four samples.

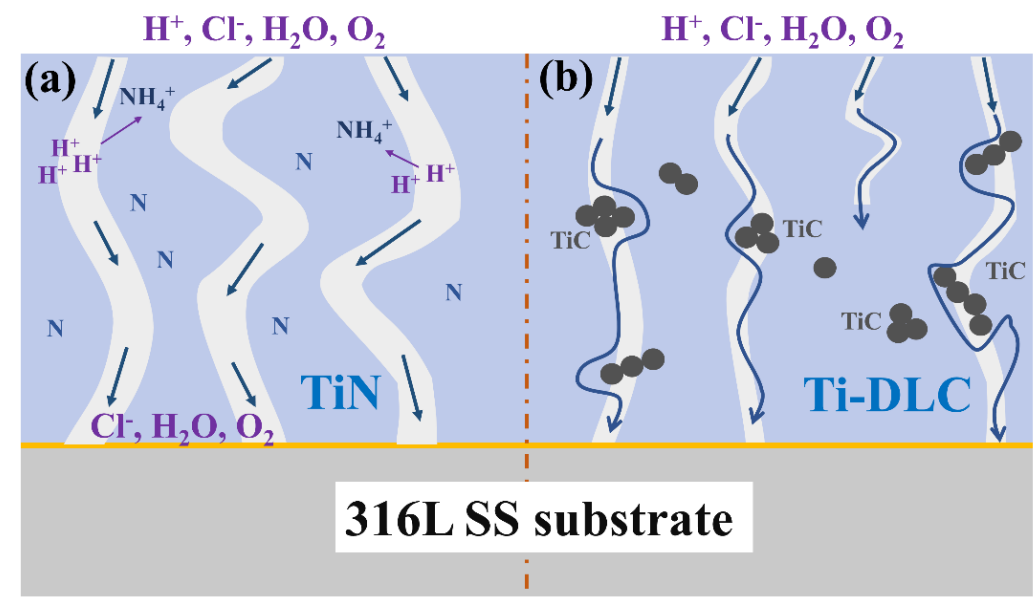

Figure 7. Protection mechanism of TiN and TiCN films in high $\mathrm{H}^{+}, \mathrm{Cl}^{-}$concentrate solution. (a) TiN; (b) Ti-DLC. 


\subsection{Surface Morphologies and Thickness of Sample after Electrochemical Tests}

The above findings are consistent with the surface morphologies of the 316L SS substrate and three films after the electrochemical tests, as shown in Figure 8. The pore size of the 316L SS substrate surface significantly increases after electrochemical tests, particularly in the electrolyte system with high $\mathrm{Cl}^{-}$and $\mathrm{H}^{+}$concentrations. Additionally, TiN and TiCN show fewer holes at low $\mathrm{Cl}^{-}$concentrations. Simultaneously at high $\mathrm{Cl}^{-}$and $\mathrm{H}^{+}$concentrations, noticeable pitting occurred on the TiN surface, and the TiCN surface became uneven. The surface of Ti-DLC was relatively smooth and complete, indicating that the Ti-DLC film could effectively reduce the corrosion tendency of 316L SS under various conditions.

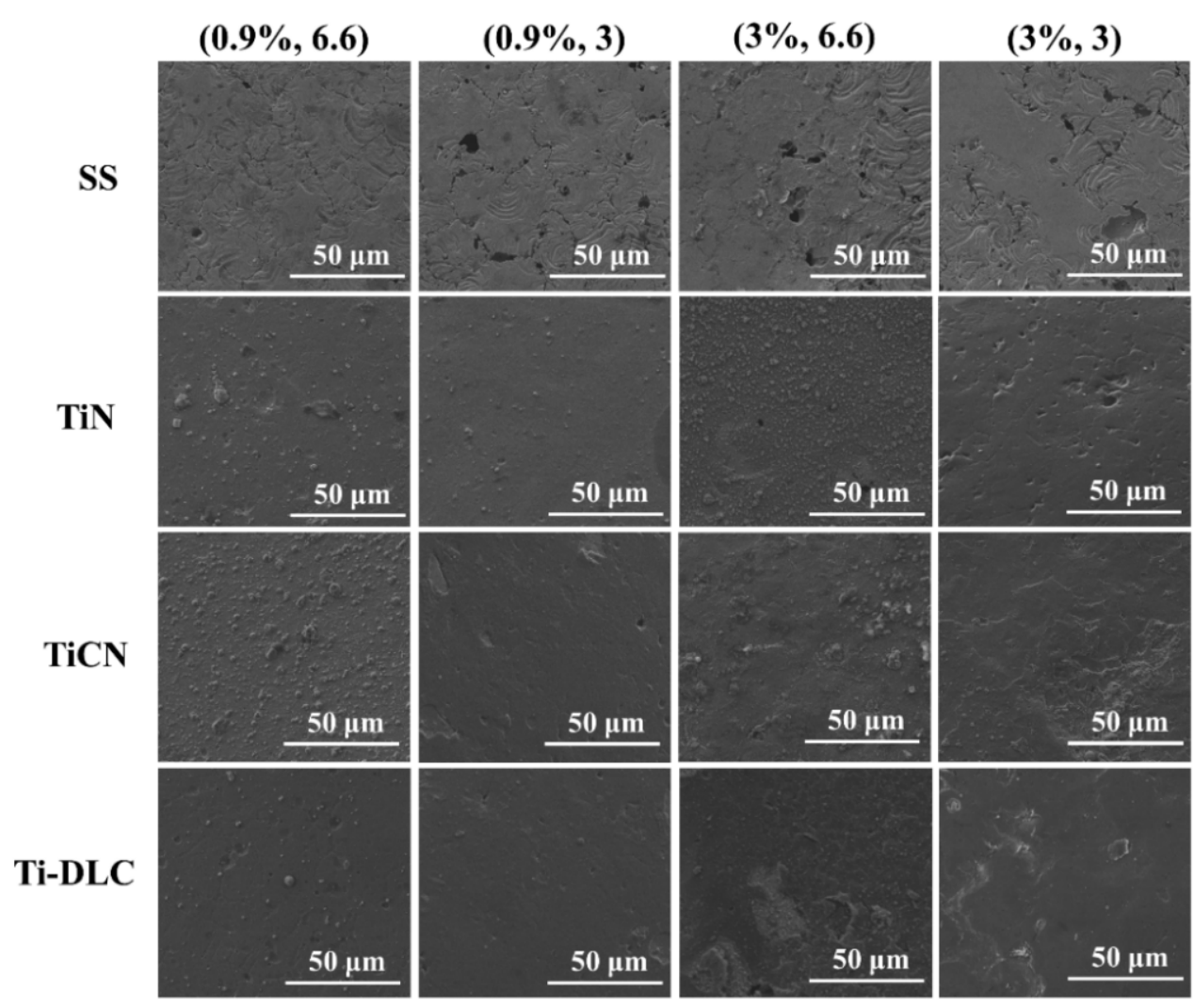

Figure 8. Surface morphologies of the four samples after electrochemical tests in different electrolytes.

Figure 9 demonstrates the cross-section morphologies of the three films after the electrochemical tests. The thicknesses of all films decrease by different amounts after the electrochemical tests. The thicknesses of TiN, TiCN and Ti-DLC reduce from 2.05, 4.10 and $4.48 \mu \mathrm{m}$ to $1.69,3.92$ and $4.36 \mu \mathrm{m}$, respectively. In case of TiCN and Ti-DLC films, their thicknesses reduced by 0.18 and $0.12 \mu \mathrm{m}$, indicating that the corrosion level of Ti-DLC is lower. The thickness of the TiN film reduced by $0.36 \mu \mathrm{m}$, proving that it has the worst corrosion resistance. 


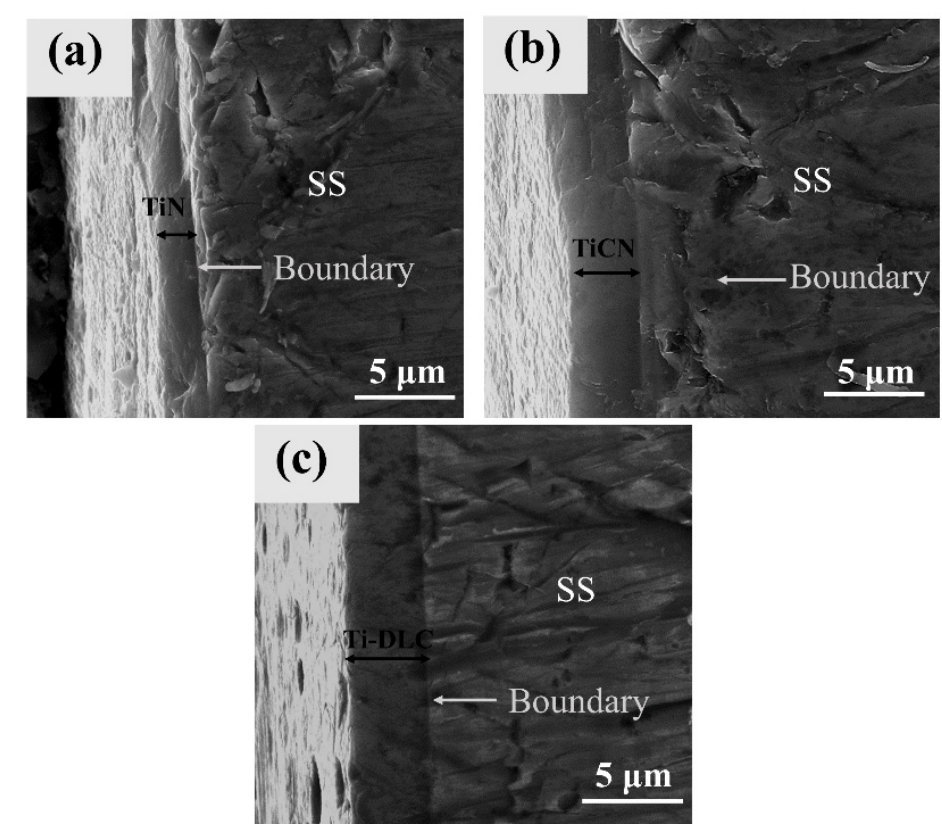

Figure 9. Cross-section morphologies of the three films after electrochemical tests. (a) TiN; (b) TiCN; (c) Ti-DLC.

\section{Conclusions}

In summary, we compared the corrosion mechanisms of TiN, TiCN and Ti-DLC coatings on 316L SS substrates to identify the best corrosion protection coating for dental braces. The main findings of the study are as follows:

(1) In the initial stage of an electrochemical tests, the stability of TiCN and Ti-DLC is inferior to 316L SS because the clusters on their surface dissolve preferentially in the artificial saliva.

(2) After the EIS tests, the clusters on TiCN and Ti-DLC film dissolved and a smooth surface was obtained. The potentiometric test results showed that the Ti-DLC film exhibited the most stable electrochemical properties, regardless of the presence of artificial saliva or electrolytes with different $\mathrm{Cl}^{-}$and $\mathrm{H}^{+}$concentrations. The excellent corrosion resistance of the Ti-DLC coating resulted from the TiC crystals obstructing the path of the corrosive species penetrating the as-deposited film.

(3) After the electrochemical tests, Ti-DLC had the smallest thickness reduction, implying that it had good chemical stability and a self-passivation effect in the electrolyte.

Author Contributions: Conceptualization, J.L. and J.Z.; methodology, J.Z.; software, Z.G.; validation, J.L., Z.G. and H.H.; formal analysis, J.Z.; investigation, J.Z.; resources, X.W.; data curation, Z.G.; writing-original draft preparation, Z.G.; writing—review and editing, J.L. and Z.G.; visualization, J.Z.; supervision, H.H.; project administration, J.Z.; funding acquisition, J.L., H.H. and X.W. All authors have read and agreed to the published version of the manuscript.

Funding: This research received no external funding by National Nature Science Foundation of China (52164042 and 51804271); The Natural Science Foundation of Hunan Province, China (2019JJ80055); Guangxi Natural Science Foundation (2018GXNSFAA281237); And Scientific Research Foundation of Hunan Provincial Education Department (19B550).

Institutional Review Board Statement: Not applicable.

Informed Consent Statement: Not applicable.

Data Availability Statement: Not applicable.

Conflicts of Interest: The authors declare that they have no conflict of interest. 


\section{References}

1. Nattrass, C.; Sandy, J. Adult orthodontics-A review. Br. J. Orthod. 1995, 22, 331-337. [CrossRef]

2. Hu, H.; Li, C.; Li, F.; Chen, J.; Sun, J.; Zou, S.; Sandham, A.; Xu, Q.; Riley, P.; Ye, Q. Enamel etching for bonding fixed orthodontic braces. Cochrane Database Syst. Rev. 2013, 1, 1-10. [CrossRef]

3. Littlewood, S.J.; Millett, D.T.; Doubleday, B.; Bearn, D.R.; Worthington, H.V. Retention procedures for stabilising tooth position after treatment with orthodontic braces. Cochrane Database Syst. Rev. 2016, 1, 1-12. [CrossRef]

4. Rezaee, S.; Arman, A.; Jurečka, S.; Korpi, A.G.; Mwema, F.; Luna, C.; Sobola, D.; Kulesza, S.; Shakoury, R.; Bramowicz, M. Effect of annealing on the micromorphology and corrosion properties of Ti/SS thin films. Superlattices Microstruct. 2020, $146,106681$. [CrossRef]

5. Khelfaoui, Y.; Kerkar, M.; Bali, A.; Dalard, F. Electrochemical characterisation of a PVD film of titanium on AISI 316L stainless steel. Surf. Coat. Technol. 2006, 200, 4523-4529. [CrossRef]

6. Mirjalili, M.; Momeni, M.; Ebrahimi, N.; Moayed, M.H. Comparative study on corrosion behaviour of Nitinol and stainless steel orthodontic wires in simulated saliva solution in presence of fluoride ions. Mater. Sci. Eng. C 2013, 33, 2084-2093. [CrossRef]

7. Vaughan, J.L.; Duncanson, M.G., Jr.; Nanda, R.S.; Currier, G.F. Relative kinetic frictional forces between sintered stainless steel brackets and orthodontic wires. Am. J. Orthod. Dentofac. Orthop. 1995, 107, 20-27. [CrossRef]

8. Zhang, J.; Ju, P.; Wang, C.; Dun, Y.; Zhao, X.; Zuo, Y.; Tang, Y. Corrosion Behaviour of 316L Stainless Steel in Hot Dilute Sulphuric Acid Solution with Sulphate and NaCl. Prot. Met. Phys. Chem. 2019, 55, 148-156. [CrossRef]

9. Paetyangkul, A.; Türk, T.; Elekdağ-Türk, S.; Jones, A.S.; Petocz, P.; Cheng, L.L.; Darendeliler, M.A. Physical properties of root cementum: Part 16. Comparisons of root resorption and resorption craters after the application of light and heavy continuous and controlled orthodontic forces for 4, 8, and 12 weeks. Am. J. Orthod. Dentofac. Orthop. 2011, 139, e279-e284. [CrossRef]

10. Alfonso, M.; Espinar, E.; Llamas, J.M.; Rupérez, E.; Manero, J.; Barrera, J.; Solano, E.; Gil, F. Friction coefficients and wear rates of different orthodontic archwires in artificial saliva. J. Mater. Sci. Mater. Med. 2013, 24, 1327-1332. [CrossRef] [PubMed]

11. Jensen, C.S.; Lisby, S.; Baadsgaard, O.; Byrialsen, K.; Menné, T. Release of nickel ions from stainless steel alloys used in dental braces and their patch test reactivity in nickel-sensitive individuals. Contact Dermat. 2003, 48, 300-304. [CrossRef]

12. Jindal, P.; Santhanam, A.; Schleinkofer, U.; Shuster, A. Performance of PVD TiN, TiCN, and TiAlN coated cemented carbide tools in turning. Int. J. Refract. Met. Hard Mater. 1999, 17, 163-170. [CrossRef]

13. Datta, S.; Das, M.; Balla, V.K.; Bodhak, S.; Murugesan, V. Mechanical, wear, corrosion and biological properties of arc deposited titanium nitride coatings. Surf. Coat. Technol. 2018, 344, 214-222. [CrossRef]

14. Liu, C.; Chu, P.K.; Lin, G.; Qi, M. Anti-corrosion characteristics of nitride-coated AISI 316L stainless steel coronary stents. Surf. Coat. Technol. 2006, 201, 2802-2806. [CrossRef]

15. Kao, C.T.; Ding, S.J.; Chen, Y.C.; Huang, T.H. The anticorrosion ability of titanium nitride (TiN) plating on an orthodontic metal bracket and its biocompatibility. J. Biomed. Mater. Res. 2002, 63, 786-792. [CrossRef] [PubMed]

16. Takadoum, J.; Houmid-Bennani, H.; Mairey, D.; Zsiga, Z. Adhesion and wear resistance of thin hard coatings. Eur. Ceram. Soc. 1997, 17, 1929-1932. [CrossRef]

17. Ren, X.; Zhao, R.; Wang, W.; Song, X.; Zhang, Y.; Zhang, C. Corrosion resistance of TiCN films prepared with combining multi-arc ion plating and magnetron sputtering technique. Rare Met. Mater. Eng. 2018, 47, 2028-2036. [CrossRef]

18. Antunes, R.; Rodas, A.; Lima, N.; Higa, O.; Costa, I. Study of the corrosion resistance and in vitro biocompatibility of PVD TiCN-coated AISI 316 L austenitic stainless steel for orthopedic applications. Surf. Coat. Technol. 2010, 205, 2074-2081. [CrossRef]

19. Cheng, Y.; Browne, T.; Heckerman, B.; Meletis, E. Influence of the C content on the mechanical and tribological properties of the TiCN coatings deposited by LAFAD technique. Surf. Coat. Technol. 2011, 205, 4024-4029. [CrossRef]

20. Huang, S.; Ng, M.; Samandi, M.; Brandt, M. Tribological behaviour and microstructure of TiCxN (1-x) coatings deposited by filtered arc. Wear 2002, 252, 566-579. [CrossRef]

21. Senna, L.; Achete, C.; Hirsch, T.; Freire, F., Jr. Structural, chemical, mechanical and corrosion resistance characterization of TiCN coatings prepared by magnetron sputtering. Surf. Coat. Technol. 1997, 94, 390-397. [CrossRef]

22. Wang, Q.; Zhou, F.; Zhou, Z.; Li, L.K.-Y.; Yan, J. Electrochemical performance of TiCN coatings with low carbon concentration in simulated body fluid. Surf. Coat. Technol. 2014, 253, 199-204. [CrossRef]

23. Jo, Y.J.; Zhang, T.F.; Son, M.J.; Kim, K.H. Synthesis and electrochemical properties of Ti-doped DLC films by a hybrid PVD/PECVD process. Appl. Surf. Sci. 2018, 433, 1184-1191. [CrossRef]

24. Zhao, F.; Li, H.; Ji, L.; Wang, Y.; Zhou, H.; Chen, J. Ti-DLC films with superior friction performance. Diam. Relat. Mater. 2010, 19, 342-349. [CrossRef]

25. Qiang, L.; Zhang, B.; Zhou, Y.; Zhang, J. Improving the internal stress and wear resistance of DLC film by low content Ti doping Solid State Sci. 2013, 20, 17-22. [CrossRef]

26. Xu, X.; Zhou, Y.; Liu, L.; Guo, P.; Li, X.; Lee, K.-R.; Cui, P.; Wang, A. Corrosion behavior of diamond-like carbon film induced by $\mathrm{Al} / \mathrm{Ti}$ co-doping. Appl. Surf. Sci. 2020, 509, 144877. [CrossRef]

27. Zhang, J.; Lou, J.; He, H.; Xie, Y. Comparative investigation on the tribological performances of TiN, TiCN, and Ti-DLC film-coated stainless steel. JOM 2019, 71, 4872-4879. [CrossRef]

28. Zhang, S.; Yan, M.; Yang, Y.; Zhang, Y.; Yan, F.; Li, H. Excellent mechanical, tribological and anti-corrosive performance of novel Ti-DLC nanocomposite thin films prepared via magnetron sputtering method. Carbon 2019, 151, 136-147. [CrossRef] 
29. Konkhunthot, N.; Photongkam, P.; Wongpanya, P. Improvement of thermal stability, adhesion strength and corrosion performance of diamond-like carbon films with titanium doping. Appl. Surf. Sci. 2019, 469, 471-486. [CrossRef]

30. Wongpanya, P.; Pintitraratibodee, N.; Thumanu, K.; Euaruksakul, C. Improvement of corrosion resistance and biocompatibility of 316L stainless steel for joint replacement application by Ti-doped and Ti-interlayered DLC films. Surf. Coat. Technol. 2021, 425, 127734. [CrossRef]

31. Zhou, Y.; Li, L.; Hu, T.; Wang, Q.; Shao, W.; Rao, L.; Xing, X.; Yang, Q. Role of TiC nanocrystalline and interface of TiC and amorphous carbon on corrosion mechanism of titanium doped diamond-like carbon films: Exploration by experimental and first principle calculation. Appl. Surf. Sci. 2021, 542, 148740. [CrossRef]

32. Pytko-Polonczyk, J.; Jakubik, A.; Przeklasa-Bierowiec, A.; Muszynska, B. Artificial saliva and its use in biological experiments. J. Physiol. Pharmacol. 2017, 68, 807-813.

33. Panjan, P.; Drnovšek, A.; Gselman, P.; Čekada, M.; Panjan, M. Review of growth defects in thin films prepared by PVD techniques. Coatings 2020, 10, 447. [CrossRef]

34. Cheng, Y.; Zheng, Y. Characterization of TiN, TiC and TiCN coatings on Ti-50.6 at.\% Ni alloy deposited by PIII and deposition technique. Surf. Coat. Technol. 2007, 201, 4909-4912. [CrossRef]

35. Zhang, S.; Zhao, H.; Shu, F.; Wang, G.; Liu, B.; Xu, B. Study on the corrosion behavior of steel Q315NS heat-affected zone in a HCl solution using electrochemical noise. RSC Adv. 2018, 8, 454-463. [CrossRef]

36. Ye, C.; Hu, R.; Dong, S.; Zhang, X.; Hou, R.; Du, R.; Lin, C.; Pan, J. EIS analysis on chloride-induced corrosion behavior of reinforcement steel in simulated carbonated concrete pore solutions. J. Electroanal. Chem. 2013, 688, 275-281. [CrossRef]

37. Alves, M.M.; Prošek, T.; Santos, C.F.; Montemor, M.F. Evolution of the in vitro degradation of Zn-Mg alloys under simulated physiological conditions. RSC Adv. 2017, 7, 28224-28233. [CrossRef]

38. Bayón, R.; Igartua, A.; González, J.; De Gopegui, U.R. Influence of the carbon content on the corrosion and tribocorrosion performance of Ti-DLC coatings for biomedical alloys. Tribol. Int. 2015, 88, 115-125. [CrossRef]

39. Carnot, A.; Frateur, I.; Zanna, S.; Tribollet, B.; Dubois-Brugger, I.; Marcus, P. Corrosion mechanisms of steel concrete moulds in contact with a demoulding agent studied by EIS and XPS. Corros. Sci. 2003, 45, 2513-2524. [CrossRef]

40. Sun, W.; Wang, L.; Wu, T.; Wang, M.; Yang, Z.; Pan, Y.; Liu, G. Inhibiting the corrosion-promotion activity of graphene. Chem. Mater. 2015, 27, 2367-2373. [CrossRef]

41. Shih, C.; Shih, C.; Su, Y.; Su, L.H.; Chang, M.; Lin, S. Effect of surface oxide properties on corrosion resistance of 316L stainless steel for biomedical applications. Corros. Sci. 2004, 46, 427-441. [CrossRef]

42. Soltis, J. Passivity breakdown, pit initiation and propagation of pits in metallic materials—Review. Corros. Sci. 2015, 90, 115-221. [CrossRef]

43. Liu, C.; Chu, P.K.; Lin, G.; Yang, D. Effects of Ti/TiN multilayer on corrosion resistance of nickel-titanium orthodontic brackets in artificial saliva. Corro. Sci. 2007, 49, 3783-3796. [CrossRef]

44. Dong, H.; Sun, Y.; Bell, T. Enhanced corrosion resistance of duplex coatings. Surf. Coat. Technol. 1997, 90, 91-101. [CrossRef]

45. Wu, Y.; Zhou, S.; Zhao, W.; Ouyang, L. Comparative corrosion resistance properties between (Cu, Ce)-DLC and Ti co-doped (Cu, Ce)/Ti-DLC films prepared via magnetron sputtering method. Chem. Phys. Lett. 2018, 705, 50-58. [CrossRef] 